\title{
As contribuições das pesquisas acadêmicas sobre Inclusão Escolar e Educação de Jovens e Adultos
}

\author{
The contributions of academic research on School Inclusion \\ and Youth and Adult Education
}

\section{Las contribuciones de la investigación académica sobre la Inserción de la Escuela y la Educación para Jóvenes y Adultos}

\author{
Maria da CONCEIÇÃo Alves FERREIRA ${ }^{1}{ }^{1}$ \\ Julimar SANTIAGO ROCHA (1) 2 \\ ${ }^{1}$ Universidade do Estado da Bahia, Salvador, BA, Brasil. \\ ${ }^{2}$ Secretaria Municipal de Educação de Salvador, BA, Brasil.
} \begin{abstract}
$\diamond$
\section{RESUMO}

Este artigo aborda o estado das pesquisas que discutem a inclusão e a Educação de Jovens e Adultos (EJA), através das seguintes proposições: as contribuições das teses e dissertações sobre Inclusão Escolar e EJA; levantamento das instituições que essas pesquisas acadêmicas se destacam com maior volume de produções; e em quais regiões do Brasil há um investimento nessa temática. Tem como objetivo mapear as teses e dissertações que abordam concomitantemente Inclusão Escolar e EJA, bem como as suas contribuições para o desenvolvimento de novos estudos. Palavras-chave: Educação de Jovens e Adultos. Inclusão. Pesquisa.
\end{abstract}

\begin{abstract}
This article discusses the state of the researches that discuss the inclusion and EJA, by means of the following propositions: the contributions of the thesis and dissertations on School Inclusion and EJA. Survey of institutions that these academic research stand out with greater volume of productions and in which regions of Brazil there is an investment in this theme. Aims to map the theses and dissertations covering at the School Inclusion and Youth Education, as well as their contributions to development of new studies.
\end{abstract}

Keywords: Adult and Youth Education. Inclusion. Research.

\section{RESUMEN}

Este artículo analiza el estado de las investigaciones que tratan sobre la inclusión y EJA, por medio de las siguientes proposiciones: las contribuciones de la tesis y disertaciones sobre Inclusión Escolar y EJA. Estudio de las instituciones que éstos investigación académica destacan con mayor volumen de producciones y en las regiones de Brasil que es una inversión en este tema. Tiene como objetivo asignar las tesis y disertaciones que abarcan en la Inclusión Escolar y Educación de la juventud, así como sus contribuciones al desarrollo de nuevos estudios.

Palabras clave: Educación de Jóvenes y Adultos. Inclusión. Investigación. 


\section{INTRODUÇÃo}

Historicamente no contexto brasileiro, a Educação de Jovens e Adultos (EJA) sempre representou um espaço de lutas contra a exclusão social. Uma outra população também submetida à exclusão são as pessoas com deficiência. Diante das mudanças políticas e sociais acerca dos direitos das minorias e dos excluídos surge a interrogação acerca das contribuições acadêmicas para estudos que apontem em direção à superação das práticas excludentes dando visibilidade para todos os sujeitos. A reorganização da educação brasileira, tendo em vista o princípio inclusivo, provocou vários questionamentos sobre a efetivação das alterações propostas; a forma como estão sendo executadas e as possibilidades de concretização dessas mudanças, bem como a formação dos professores para lidar com os desafios advindos dessa nova realidade, entre outros.

Muitas pesquisas têm discutido o modo como vem ocorrendo a inclusão escolar no Brasil, quais os problemas encontrados na implementação dessa política e quais as possíveis soluções para lidar com as dificuldades vivenciadas nesse processo. A nossa busca, porém, é por pesquisas que discutam concomitantemente a inclusão e a EJA, através dos seguintes questionamentos: quais as contribuições das teses e dissertações sobre inclusão escolar e EJA? Em quais instituições essas pesquisas acadêmicas se destacam com mais volume de produções e em quais regiões do Brasil há um investimento nessa temática? Tem como objetivo mapear teses e dissertações que abordem concomitantemente inclusão escolar e EJA, bem como as suas contribuições para o desenvolvimento de novos estudos. O interesse pela pesquisa é motivado pela implicação das pesquisadoras com o objeto de estudo, por meio da atuação como gestora escolar e pesquisadoras na Modalidade da EJA. Os questionamentos emergem na trajetória inicial da investigação ao buscarmos analisar o processo de inclusão de educandos com deficiência na EJA levantando, assim, as contribuições e lacunas existentes nas pesquisas produzidas no País.

\section{A metodologia e as pesquisas}

As pesquisas de caráter bibliográfico permitem ao investigador a compreensão dos fenômenos de uma forma ampla através de material já elaborado e que atualmente compõe o repositório das produções acadêmicas. Para Soares (1989) são de grande importância, pois podem conduzir à plena compreensão do estado atingido pelo conhecimento a respeito de determinado tema, as opções teóricas e metodológicas adotadas, sua amplitude, bem como as lacunas a serem preenchidas. Esse tipo metodológico de pesquisa é geralmente intitulado como
"Estado da Arte". Mas verifica-se ser comum receber outras denominações, tais como "Síntese Integrativa" (ANDRÉ, 2002), "Trabalhos Inventariantes" (SOARES; MACIEL, 2000), "Pesquisas que estudam pesquisas" (SLONGO, 2004), "Estado da arte" e "Estado do conhecimento" (ROMANOWSKI; ENS, 2006). Para Ferreira (2002) esses estudos têm como finalidade mapear como as produções acadêmico-científicas têm sido realizada, quais aspectos têm sido destacados, e as lacunas encontradas em dado período.

A análise proposta aqui encontra-se respaldada em Romanowski e Ens (2006) sendo, portanto, um estado do conhecimento. Os autores diferenciam estado da arte de estado do conhecimento. A realização do primeiro, parte não apenas do estudo dos resumos de dissertações e teses, mas também dos estudos sobre as produções e congressos na área, e estudos sobre as publicações em periódicos na área investigada. Já o estado do conhecimento é: “[...] o estudo que aborda apenas um setor das publicações sobre o tema estudado" (ROMANOWSKI; ENS, 2006, p.40). Como nesta pesquisa analisamos somente os trabalhos realizados em cursos stricto sensu, apenas um setor de produção dessas pesquisas, reafirmamos que se trata de um estado do conhecimento. Dessa forma, o texto incide sobre o conjunto das pesquisas realizadas em universidades brasileiras, sejam elas públicas ou privadas. $\mathrm{O}$ interesse por considerar apenas as teses $\mathrm{e}$ dissertações se justifica pela intenção de analisar o que tem sido produzido pelos programas de pós-graduação stricto sensu nas universidades brasileiras acerca da temática, pois cumprem um importante papel na produção científica. Segundo Severino (2006, p.51-52), a pósgraduação no Brasil se transformou em uma:

[...] sementeira de pesquisadores, o que contribuiu para a consolidação do quadro de recursos humanos para todos os setores da vida nacional. Pode-se afirmar com segurança que a pós-graduação é um dos melhores segmentos do sistema educacional brasileiro sob o critério do nível de qualidade alcançado e vem contribuindo significativamente para a construção de um retrato mais fiel da realidade nacional, graças à sistematização e à institucionalização da prática científica de investigação, ao mesmo tempo em que forma novas gerações de pesquisadores.

A pós-graduação mesmo enfrentando problemas relacionados à gestão administrativa e política, tem conseguido contribuir para a ampliação de práticas científicas, além de investir na formação de pesquisadores e docentes. Essas contribuições constituem a universidade como agência produtora de conhecimento, e de grande relevância para avanços educacionais, políticos e sociais. As pesquisas do tipo estado da arte emergem nesse 
cenário para avaliar não apenas a quantidade do que tem sido produzido em determinado período histórico, mas a qualidade das produções e os diferentes enfoques, sendo um instrumento importante para novos mestres e doutores que têm iniciado o seu processo de pesquisa.

Escolhemos o período de 2008 a 2016, primeiro por serem pesquisas mais atuais e, por 2008 ser o ano de publicação da Política Nacional da Educação Especial na perspectiva da Educação Inclusiva pelo Ministério da Educação (PNEE). Essa política acompanha os avanços das lutas sociais, visando constituir políticas públicas promotoras de uma educação de qualidade para todos os alunos, de forma a assegurar condições de igualdade, bem como o exercício dos direitos, visando à inclusão social e à cidadania para todos indistintamente.

Com o objetivo de elucidar as questões descritas acima partimos para o levantamento e a identificação das teses e das dissertações indexadas na Biblioteca Digital Brasileira de Teses e Dissertações (BDTD) encontradas no endereço eletrônico oficial disponibilizado pelo Instituto Brasileiro de Informação em Ciência e Tecnologia (Ibict). ${ }^{1}$ Esta busca foi realizada através de uma associação em pares entre os seguintes descritores: "EJA"; "educação de jovens e adultos"; "educação especial”; "educação inclusiva"; e "inclusão". Durante esse levantamento foram selecionadas as pesquisas que apresentaram os descritores em seus títulos, resumos ou palavras-chave; que estavam circunscritas ao campo da inclusão escolar ou que tivessem como foco a inclusão de pessoas com deficiência na EJA, e que foram defendidas entre os anos de 2008 e 2016.

\section{RESULTADOS E DISCUSSÕES}

Inicialmente, encontramos 974 trabalhos, sendo 669 teses e 305 dissertações, dos quais foram selecionados, considerando os critérios de inclusão e a interface entre EJA e inclusão escolar. Excluímos aqueles que não se enquadravam nos critérios ou por serem trabalhos repetidos. Após leitura dos resumos dos trabalhos selecionados foi realizada uma triagem, que resultou na escolha de 21 dissertações e 5 (cinco) teses produzidas em diferentes regiões brasileiras que têm como foco a interlocução entre a EJA e a inclusão escolar.

A princípio os trabalhos foram classificados considerando as temáticas abordadas ao tratar a EJA e a inclusão escolar. Conseguimos categorizar em 8 (oito) eixos: Inclusão escolar; Práticas pedagógicas; Processos de ensino e aprendizagem; Direito à educação: indicadores educacionais; Processo de escolarização; Formação de professores; Formação para o mundo do trabalho; e,

\footnotetext{
$\overline{1}$ Disponível em: http://bdtd.ibict.br/vufind/. Acesso em: 7 de nov. 2017.
}

Políticas públicas. A maioria das temáticas encontradas apontam para o processo de ensino-aprendizagem, práticas pedagógicas, inclusão escolar e formação de professores, perfazendo um total de $80 \%$ das pesquisas. Esses temas dialogam diretamente para o olhar voltado para o investigado principal: o professor. Barbosa, Alves e Souza (2014, p.107), afirmam que: "A formação de professores precisa ser entendida como um dos fatores para que a educação inclusiva dê um salto qualitativo". Essa percepção nos remete a formação de educadores para atuar na diversidade, proporcionando uma educação de qualidade.

Passamos depois a nos debruçar sobre o local de defesa das pesquisas e as respectivas instituições. Quais instituições se destacam com maior volume das produções em estudo? Em quais regiões do Brasil há um maior debruçar sobre as temáticas? Dos trabalhos analisados em 16 universidade brasileiras apenas 25\% das instituições eram privadas, as demais eram públicas de diferentes esferas: federais e estaduais. Segundo Chauí (2003), as universidades públicas são instituições sociais que acompanham as transformações da sociedade e que dispõem de autonomia intelectual. Diante disso, as pesquisas por elas produzidas precisam ser valorizadas e publicizadas, como meio de superação de paradigmas ultrapassados, apontando para novas formas de convivência.

Na Tabela 1, adiante, é possível ver que dentre as 16 instituições, a Universidade Federal de São Carlos (UFSCAR), em São Paulo, concentra um maior volume de produções, o equivalente a $23 \%$, com 4 (quatro) dissertações e 2 (duas) teses que trazem uma relação entre a educação de adultos e a questão da educação inclusiva. As teses são escassas aparecendo apenas em quatro universidades.

Buscando compreender porque a UFSCAR encontra-se em evidência quanto ao quantitativo dos trabalhos acadêmicos, realizamos uma busca no site da referida universidade e descobrimos que a mesma conta com um Programa de Pós-Graduação em Educação Especial (PPGEEs). Foi o primeiro Programa de Pós-Graduação em Educação Especial implantado no País, e desde então se constitui no único programa específico na área. Habilitou 581 mestres e 160 doutores até dezembro de 2016, o que representa um contingente substancial de recursos humanos qualificados para o Ensino Superior, com um enorme potencial multiplicador. A estrutura curricular do programa perpassa por três áreas: Docência universitária, Pesquisa em Educação Especial e Assessoria a programas e serviços de Educação Especial para pessoas com deficiência intelectual. Consideramos que mesmo a universidade com essa especificidade ainda apresenta um quantitativo mínimo para a questão do aluno com 
Tabela 1 - Total de pesquisas por natureza (tese ou dissertação) nas universidades brasileiras

\begin{tabular}{lccc}
\hline Instituições & Dissertações & Teses & Total \\
Universidade Federal de São Carlos & 04 & 02 & 06 \\
Universidade Estadual Paulista & 02 & 01 & 03 \\
Universidade Federal do Espírito Santo & 03 & - & 03 \\
Universidade Federal de Minas Gerais & 02 & - & 02 \\
Universidade do Estado do Rio de Janeiro & 01 & - & 01 \\
Universidade do Grande Rio & 01 & 01 & 01 \\
Pontifícia Universidade Católica de São Paulo & - & - & 01 \\
Universidade de São Paulo & 01 & - & 01 \\
Universidade Estadual de Londrina & 01 & - & 01 \\
Universidade do Vale do Rio dos Sinos & 01 & - & 01 \\
Universidade Federal do Rio Grande do Sul & 01 & 01 & 01 \\
Pontifícia Universidade Católica do Rio Grande do Sul - Porto Alegre & & - & 01 \\
Universidade Regional de Blumenau & 01 & - & 01 \\
Universidade Federal do Rio Grande do Norte & 01 & - & 01 \\
Universidade Federal da Paraíba & 01 & - & 01 \\
Universidade Federal de Pernambuco & 01 & 01 \\
TOTAL & & & 26 \\
\hline
\end{tabular}

Fonte: Elaborado pelas pesquisadoras na análise das pesquisas em 2017.

deficiência nas classes de educação de jovens e adultos. Mas, aponta para um despertar sobre esses sujeitos que em muitos momentos ficam como invisíveis no processo educacional. Ireland (2016) aponta para a complexidade do fenômeno da visibilidade e invisibilidade dos sujeitos da EJA e que dentro dessa população há aqueles ainda mais emblemáticos: as pessoas com deficiência, as que estão em situação de privação e restrição de liberdade, e as pessoas idosas.

Ainda sobre o local das produções a Região Sudeste, em particular o estado de São Paulo, lidera o ranking com 18 trabalhos, conforme vemos no Gráfico 1. Em contrapartida, na Região Nordeste encontramos apenas 3 (três) trabalhos de dissertação: dois abordam práticas pedagógicas e um a formação de professores. Já nas Regiões Centro-Oeste e Norte não encontramos nenhuma produção. De acordo com o Censo 2010, essas duas últimas regiões são as que apresentam menor incidência de pessoa com pelo menos um tipo de deficiência. Já a Região Nordeste teve a maior taxa de prevalência de pessoas com pelo menos uma das deficiências, tendência que foi mantida desde o Censo de 2000, quando a taxa foi a maior entre as regiões brasileiras. Os dados apontam a necessidade do aumento de pesquisas na Região Nordeste como forma de suscitar políticas públicas que atendam a pessoa com deficiência que se encontra na EJA. E possa, também, discutir a ligação da deficiência com a pobreza.
Gráfico 1 - Pesquisas sobre EJA e inclusão nas regiões brasileiras

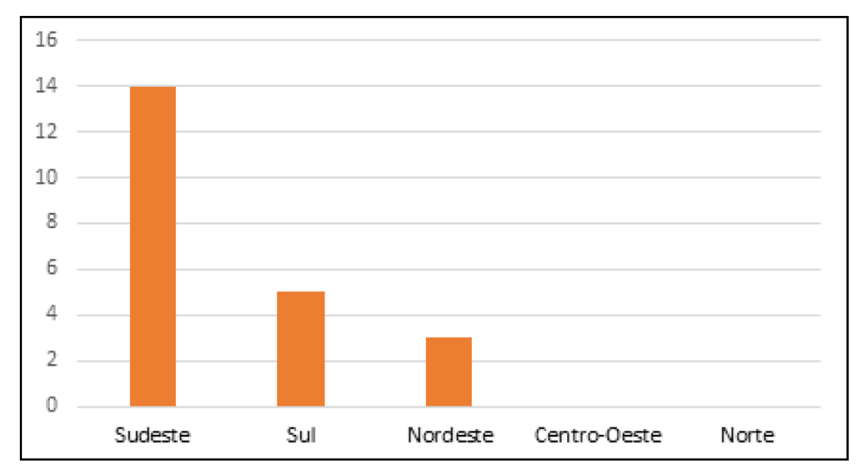

Fonte: Elaborado pelas pesquisadoras na análise das pesquisas em 2017.

Constatamos também o crescimento ascendente de trabalhos a partir do ano de 2008, após a PNEE, embora ainda consideremos um número limitado de pesquisas. Há uma maior concentração no período de 2012-2014, conforme pode ser visto na Tabela 2, a seguir. De modo geral, os trabalhos trazem como principal aspecto a investigação em contextos socioeducacionais, tendo a escola como principal lócus de investigação. Visam a transformação desses espaços a partir da intervenção através da parceria entre pesquisador e profissionais da educação. Mudanças que se baseiam, principalmente, na problematização das práticas executadas pelos 
profissionais envolvidos e nas reflexões sobre os seus fazeres, buscando melhorá-los. Os trabalhos apontam também para discussões sobre a inclusão do adolescente e jovem com deficiência na EJA, enfatizando a concretização das políticas públicas inclusivas para a garantia do direito desses sujeitos. Emergem como necessárias para o repensar da educação baseado no princípio inclusivo, bem como o respeito à diversidade que é característica fundante da EJA e de nossa sociedade atual.

Tabela 2 - Produções por temporalidade e natureza das pesquisas

\begin{tabular}{cccc}
\hline Ano & Dissertações & Teses & Total \\
2008 & 01 & & 01 \\
2009 & 02 & & 02 \\
2010 & 01 & 01 & 02 \\
2011 & 03 & & 03 \\
2012 & 06 & & 06 \\
2013 & 03 & 02 & 05 \\
2014 & 03 & 01 & 04 \\
2015 & 02 & & 02 \\
2016 & & 01 & 01 \\
Total & & & 26 \\
\hline
\end{tabular}

Fonte: Elaborado pelas pesquisadoras com base na análise das pesquisas em 2017.

As produções de teses e dissertações das universidades brasileiras analisadas aqui, apontam para um olhar diferenciado de muitos pesquisadores que já têm se debruçado sobre a inclusão escolar dos alunos com deficiência que têm chegado às classes de educação de jovens e adultos. As pesquisas indicam que a transformação precisa ocorrer na escola para que o princípio inclusivo seja consolidado ao discutir as práticas pedagógicas, o processo de ensino-aprendizagem, e principalmente a formação do professor. Constatamos também, o crescimento ascendente de trabalhos a partir do ano de 2008, após a Política Nacional da Educação Especial na perspectiva da Educação Inclusiva, embora ainda consideremos um número limitado, com uma concentração principalmente nos anos de 2010 a 2014. Ressaltamos ainda que as produções são praticamente exclusivas no âmbito de mestrado, sendo escassas na formação de doutores.

\section{CONSIDERAÇÕES FINAIS}

Percebemos que as contribuições das pesquisas analisadas frutificam mais no terreno das universidades públicas, o que revela a necessidade de um fortalecimento dessas instituições para a superação de práticas excludentes nas escolas brasileiras. As produções se concentram em apenas duas regiões do Brasil, trazendo uma contradição: a Região Nordeste, que mais apresenta pessoas com deficiência, é a que menos produz trabalhos voltados para esse público. Além de apresentar a lacuna de pesquisas nas Regiões Norte e Centro Oeste. Recomendamos a realização de outros estudos que discutam concomitantemente a inclusão escolar e a EJA de forma a fortalecer essa modalidade, bem como a diversidade dos sujeitos que a compõe. Consideramos que a criação de repositórios acadêmicos online viabiliza o estado do conhecimento, investindo diretamente na formação de novos pesquisadores que se beneficiam de forma rápida e prática de um conhecimento sistematizado por outros. Com base nos resultados apresentados, é possível indicar aos Programas de Pós-Graduação stricto sensu, principalmente aqueles voltados à Educação de Jovens e Adultos, e Educação Especial, investir nos temas menos abordados, com o intuito de fomentar pesquisas nos lugares ainda sedentos, de maneira a ampliar e diversificar a pesquisa em EJA e inclusão escolar.

\section{REFERÊNCIAS}

ANDRÉ, Marli Eliza Damaso Afonso de (org.). Formação de professores no Brasil (1990-1998). Série Estado do Conhecimento. Brasília: MEC/INEP/COMPED, 2002.

BARBOSA, Josilene Souza Lima; ALVES, Márcia Mesquita Cardoso; SOUZA, Rita de Cácia Santos. Escolas inclusivas e capacitação dos professores. In: NASCIMENTO, Eliane de Sousa; CORREIA, Patrícia Carla da Hora; PORTELA, Cláudia Paranhos de Jesus. Dialogando com a inclusão II: curso de formação de professores. Recife: Liceu, 2014. p. 98-108. https://doi.org/10.17648/galoa-cbee-6-30302

BRASIL. Ministério da Educação. Secretaria de Educação Especial. Política Nacional de Educação Especial na Perspectiva da Educação Inclusiva. Brasília: DF, 2008. Disponível em: http://portal.mec.gov.br/arquivos/pdf/ politicaeducespecial.pdf. Acesso em: 25 abr. 2017. https://doi. org/10.17648/galoa-cbee-6-29723

CHAUÍ, Marilena. A universidade pública sob nova perspectiva. Revista Brasileira de Educação, São Paulo, v. 1, n. 24, p. 5-15, dez. 2003. https://doi.org/10.1590/s141324782003000300002

FERREIRA, Norma Sandra de Almeida. As pesquisas denominadas "estado da arte". Educação \& Sociedade, São Paulo, ano 23, n. 79, p. 257-272, ago. 2002. https://doi, org/10.1590/s0101-73302002000300013

IBGE. Censo Demográfico 2010 - Características Gerais da População, religião e pessoas com deficiência. Rio de Janeiro: IBGE, 2012. Acompanha 1 CD-ROM. Disponível em: ftp://ftp.ibge.gov.br/Censos/Censo_Demografico_2010/ Caracteristicas_Gerais_Religiao_Deficiencia/caracteristicas religiao_deficiencia.pdf. Acesso em: 10 mar. 2017. https://doi. org/10.5752/p.2175-5841.2012v10n28p1122 
ROMANOWSKI, Joana Paulin; ENS, Romilda Teodora. As pesquisas denominadas do tipo "Estado da arte" em educação. Revista Diálogo Educacional, Curitiba, v. 6, n. 19, p. 37-50, set./dez. 2006. Disponível em: http://www2.pucpr.br/reol/pb/ index.php/dialogo?dd1=237\&dd99=view \&dd98=pb. Acesso em: 15 set. 2018. https://doi.org/10.7213/rde.v12i37.4810

SEVERINO, Antonio Joaquim. A avaliação no PNPG 20052010 e a política de pós-graduação no Brasil. In: FERREIRA, Naura Syria Carapeto (org.). Políticas públicas e gestão da educação: polêmicas, fundamentos e análises. Brasília: Líber Livro, 2006. p. 51-74.

SLONGO, Iône Inês Pinsson. A produção acadêmica em ensino de Biologia: um estudo a partir de teses e dissertações. 2004. 349f. Tese (Doutorado em Educação) - Centro de Ciências da Educação da Universidade Federal de Santa Catarina, Florianópolis, 2004. https://doi.org/10.24873/j. rpemd.2017.11.026

SOARES, Magda Becker; MACIEL, Francisca (org.). Alfabetização. Brasília: MEC/Inep, 2000. 173 p. (Série Estado do Conhecimento, 1).

SOARES, Magda B. Alfabetização no Brasil: o Estado do Conhecimento. Brasília: INEP/Santiago: Reduc, 1989.

Recebido em: 30/3/2019.

Aprovado em: 17/9/2019.

Publicado em: 15/12/2019.

Endereço para correspondência: Maria da Conceição Alves Ferreira Rua João José Rescala, 209, Cond. Vila Anaiti Edifício Único Residencial, apto 604 - Imbuí 41720-000, Salvador, Bahia, Brasil

Julimar Santiago Rocha

Rua Pasquale Gatto, 760, Condomínio Flex Piatã

Torre Energia, apt. 1002 - Piatã

41650-470, Salvador, Bahia, Brasil

\section{Autores:}

Maria da Conceição Alves Ferreira

Universidade do Estado da Bahia (UNEB). Salvador/BA, Brasil. Doutora em Educação pela Universidade Federal do Rio Grande do Norte, UFRN, Natal, Rio Grande do Norte, Brasil. Professora adjunta da Universidade do Estado da Bahia. Professora e orientadora do Programa de Mestrado Profissional de Educação de Jovens e Adultos da UNEB. Salvador, Bahia, Brasil.

Orcid: http://orcid.org/0000-0002-9408-2750

E-mail: consinha@terra.com.br

Julimar SANTIAgo Rocha

Secretaria Municipal de Educação de Salvador. Salvador/BA - Brasil. Mestre em Educação de Jovens e Adultos - MPEJA pela Universidade do Estado da Bahia (UNEB). Gestora na EJA na Rede Municipal de Salvador, Membro do Grupo de Pesquisa Gestão, Organização e Políticas Públicas em Educação - GEPE. Orcid: http://orcid.org/0000-0003-2659-0400

E-mail: rocha.juli12@hotmail.com 